
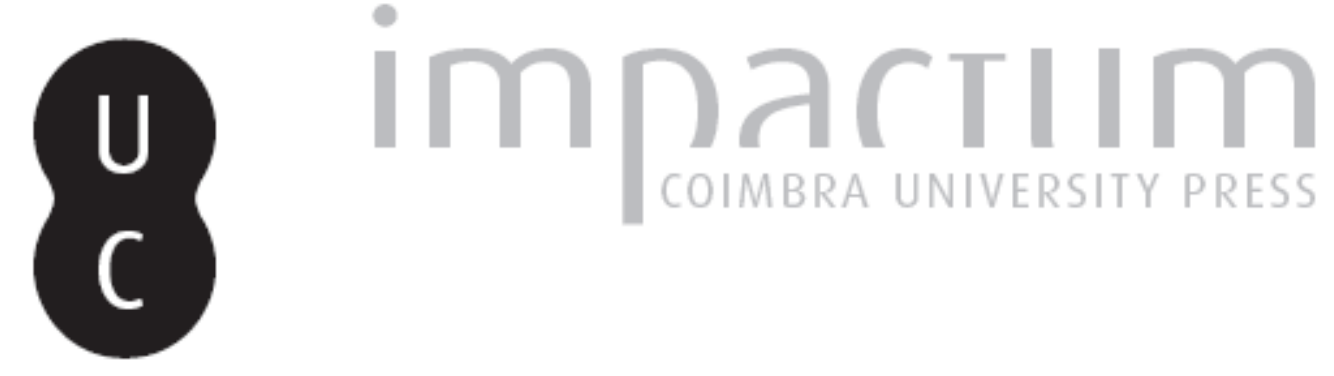

\title{
O cinema e a História: compreensão da dinâmica cronotópica das migrações contemporâneas a partir do filme "The Immigrant", de Charlie Chaplin (1917)
}

Autor(es): $\quad$ Castro, Fátima Velez de

Publicado por: Imprensa da Universidade de Coimbra

URL persistente:

URI:http://hdl.handle.net/10316.2/43246

DOI:

DOI:https://doi.org/10.14195/0870-4147_48_10

Accessed : $\quad$ 26-Apr-2023 10:36:51

A navegação consulta e descarregamento dos títulos inseridos nas Bibliotecas Digitais UC Digitalis, UC Pombalina e UC Impactum, pressupõem a aceitação plena e sem reservas dos Termos e Condições de Uso destas Bibliotecas Digitais, disponíveis em https://digitalis.uc.pt/pt-pt/termos.

Conforme exposto nos referidos Termos e Condições de Uso, o descarregamento de títulos de acesso restrito requer uma licença válida de autorização devendo o utilizador aceder ao(s) documento(s) a partir de um endereço de IP da instituição detentora da supramencionada licença.

Ao utilizador é apenas permitido o descarregamento para uso pessoal, pelo que o emprego do(s) título(s) descarregado(s) para outro fim, designadamente comercial, carece de autorização do respetivo autor ou editor da obra.

Na medida em que todas as obras da UC Digitalis se encontram protegidas pelo Código do Direito de Autor e Direitos Conexos e demais legislação aplicável, toda a cópia, parcial ou total, deste documento, nos casos em que é legalmente admitida, deverá conter ou fazer-se acompanhar por este aviso.

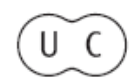




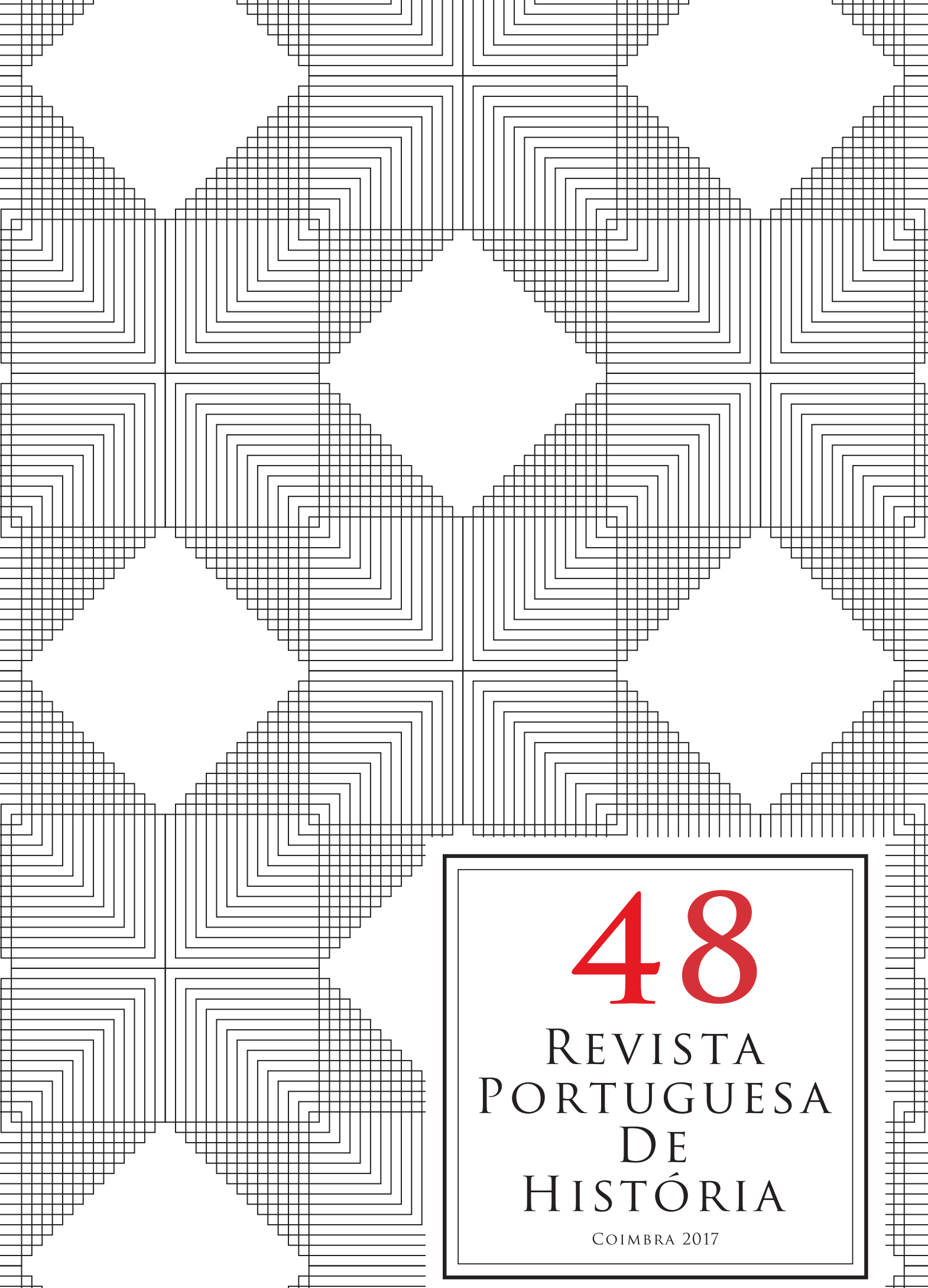




\title{
O Cinema e a História: compreensão da dinâmica cronotópica das migrações contemporâneas a partir do filme "The Immigrant", de Charlie Chaplin (1917)
}

\author{
Cinema and History: Understanding the Chronotopic \\ Dynamics of Contemporary Migrations from Charlie Chaplin's \\ The Immigrant (1917)
}

\author{
Fátima Velez de Castro \\ Departamento de Geografia e Turismo / CEGOT \\ Faculdade de Letras da Universidade de Coimbra \\ velezcastro@fl.uc.pt
}

Texto recebido em/Text submitted on: 31/01/2017

Texto aprovado em/Text approved on: 12/06/2017

\section{Resumo:}

Neste artigo pretende-se refletir sobre a relação entre o cinema e a história, considerando-se o filme como objeto de análise e instrumento de investigação, assim como construtor de ambientes históricos e de paisagens. Será por isso discutido o papel do cinema como produtor/reprodutor de momentos e de espaços, sendo invocadas e discutidas as posições de autores como Smith (1976), Ferro (1998), Kaes (1990), Morettin (2004), Protat (2009), Reigada (2013), entre outros. Tendo como base esta linha de ideias, assim como tomando em conta a dinâmica das migrações contemporâneas, será apresentado um estudo de caso que contribuirá para a compreensão dos sistemas migratórios transoceânicos do séc. XX. Para isso será realizada a análise de conteúdo do filme "The Immigrant" (1917), de Charlie Chaplin, tendo como foco a relação entre tempo, espaço e imagem fílmica.

Palavras-chave:

cinema; história; migrações; Charlie Chaplin.

\section{Abstract:}

In this article it is intended to reflect on the relationship between cinema and history, considering the film as an object of analysis and an instrument of research, as well as a builder of historical environments and landscapes. Therefore, it will be discussed the cinema's role as the producer/reproducer of moments and spaces, being cited and discussed the positions of authors such as Smith (1976), Ferro (1998), Kaes (1990), Moretti (2004), Protat (2009), Reigada (2013), amongst others. Based on this line of ideas, as well as taking into account the dynamics of contemporary migrations, it will be presented a case study which will contribute towards the understanding of transoceanic migration systems in the 20th century. In order to do that, it will be conducted a content analysis of the movie "The Immigrant" (1917), by Charles Chaplin, being focused the relation between time, space and movie image.

Keywords:

cinema; history; migration; Charlie Chaplin. 


\section{O Cinema e a História na compreensão do cronotopos}

O estudo de fenómenos científicos em Ciências Sociais e Humanas requer a diversificação das fontes de pesquisa, assim como dos instrumentos de trabalho. A ideia é que a aproximação à realidade fatual se faça da forma mais fidedigna possível, gerando a possibilidade de construção de um corpus teórico-prático sólido e passível de ser utilizado noutros contextos académicos e científicos.

A História e a Geografia são duas ciências que trabalham com base neste escopo, dada a própria relação intrínseca entre a dimensão epistemológica e a metodológica. O geógrafo Milton Santos refere-se a esta íntima conexão, ao defender que não há espaço sem tempo, pois considera que “(...) o espaço é, em si mesmo, obrigatoriamente, um conteúdo em tempo..." Francisca Azevedo ${ }^{2}$, tendo em conta a perspetiva de Holquist ${ }^{3}$, considera a associação de ambas dimensões, utilizando para isso o conceito de "cronotope", o qual se refere à inseparabilidade do espaço-tempo.

A representação deste encadeamento, materializada tanto nos fenómenos históricos como nos geográficos, pode ser analisada a partir do cinema. Juan Lez ${ }^{4}$ invoca Sargent, ao referir que as obras fílmicas tendem a se acercar do tempo e do espaço da realidade focada nos enredos. Essa opção está relacionada com uma componente utilitária, pois é uma forma de atrair a atenção do público. A utilidade também se manifesta não apenas na representação de fenómenos, mas na própria produção de contextos específicos. Sobre esta ideia, Fernandes ${ }^{5}$ defende que o cinema permite construir espaços diversos, como é o caso da "cidade-encenação", onde se viaja pelo tempo e pelo espaço numa lógica paralela à realidade, a qual é construída com base em fragmentos histórico-geográficos. Ainda na relação entre a História a Geografia, Deshpand ${ }^{6}$ enfatiza a importância do cinema para a atual análise e interpretação dos espaços urbanos do final do séc. XIX, princípio do séc. XX, a partir de excertos fílmicos que evidenciaram

\footnotetext{
${ }^{1}$ Milton Santos, A natureza do espaço: técnica e tempo, razão e emoção, S. Paulo Editora da Universidade de S. Paulo, 4. ${ }^{a}$ edição, 2006, p. 28.

${ }^{2}$ Ana Francisca Azevedo, Geografia e Cinema. Representações culturais do espaço, lugar e paisagem na cinematografia Portuguesa, Braga, Universidade do Minho, 2006, p. 440.

${ }^{3}$ Michael Holquist, Dialogism, Londres e Nova Iorque, Routledge, 2002, p. 84.

${ }^{4}$ Juan A. Hernández Lez, Cinema e Literatura. A metáfora visual, Porto, Campo das Letras, 2003, p. 71.

${ }^{5}$ João Luís Fernandes, "A paisagem urbana simbólica enquanto território efémero de celebração do marketing territorial - o caso particular das Christmascapes", Atas do VII Congresso da Geografia Portuguesa, (2004), p. 5.

${ }^{6}$ Anirudh Deshpand, "Films as historical sources or alternative history", Economic and Political Weekly, 2-8 (2004), p. 4458.
} 
tanto os edifícios, como as vias de comunicação, espaços industriais e outros, assim como das comunidades de utilizadores e as suas quotidianidades sociais e territoriais. Neste sentido, considera-se o filme como uma exotopia, no sentido em que se trata de um produto resultante de um olhar externo e condicionado pela visão do realizador. Isto faz do cinema uma representação temporal e espacial de determinados contextos, sendo útil por colocar ao espetador e ao investigador cenários hipotéticos da realidade.

Focando a discussão na especificidade da História, destacam-se os trabalhos de Marc Ferro ${ }^{7}$, sendo que este historiador entende o cinema como um agente histórico, uma vez que o seu uso permitiu apresentar momentos do passado adaptado aos propósitos de regimes políticos vigentes. Protat ${ }^{8}$ invoca o paradigmático exemplo do documentário "Triumph des Willens" (1935), de Leni Riefensthal, como objeto de propaganda do regime nazi.

Anton $\mathrm{Kaes}^{9}$ concorda com esta ideia, ao enfatizar o papel dos realizadores de cinema, pois considera-os como agentes de disseminação do conhecimento histórico, já que conseguem atingir um público mais vasto do que o académico, nomeadamente o cidadão comum. Ou seja, entende que as obras fílmicas conseguem passar a mensagem de uma forma socialmente transversal, abarcando setores populacionais mais vastos. Considera que os filmes têm o poder de manipular os telespetadores, pela forma como as histórias são contadas, ou seja, apelando-se às emoções, as quais acabam por ficar impressas na memória individual.

Daqui se depreende que a relação entre o cinema e a História é complexa, e está limitada por duas dimensões: por um lado, apela aos conhecimentos históricos; por outro, dá a liberdade para contar os fatos mediante a interpretação do realizador. É por isso que Moretin vem afirmar que “(...) um filme pode abrigar leituras opostas acerca de um determinado fato, fazendo desta tensão um dado intrínseco à sua própria estrutura interna. A perceção desse movimento deriva do conhecimento específico do meio (... ${ }^{10}$.

Tendo em conta esta perspetiva, defende-se que o papel do historiador é fundamental, tanto a montante como a jusante do processo de produção fílmica: a montante, no sentido de participar na produção e realização dos conteúdos

\footnotetext{
${ }^{7}$ Marc Ferro, Cinema and history, Detroit, Wayne State University Press, 1998, p. 14.

${ }^{8}$ Zoé Protat (2009), "Cinéma et histoire: reconstruir les temps, ressentir l'histoire", Ciné-Bulles, 27-2 (2009), p. 44.

${ }^{9}$ Anton Kaes, "History and Film: public memory in the age of electronic dissemination", History and Memory, 2-1 (1990), p. 112.

${ }^{10}$ Eduardo Victorio Morettin, "O cinema como fonte histórica na obra de Marc Ferro", História: questões e debates, 38 (2003), p. 15.
} 
audiovisuais, para evitar imprecisões científicas ou distorções fatuais; a jusante, para ajudar o telespetador a entender os conteúdos fílmicos, aproximando-o da verdadeira natureza dos acontecimentos.

Atente-se na ideia de Tiago Reigada ${ }^{11}$, o qual afirma que, do ponto de vista da História cultural, o cinema começou por "imitar", ou seja, representar uma determinada realidade social. Numa fase posterior, passou a "construir" a realidade através de representações da mesma. Este é um ponto em que podemos considerar que a História e a Geografia se tocam, no que diz respeito à sua relação com o cinema. O filme materializa uma dimensão cronotópica diferenciada do que se considera "real", seja porque se baseia na construção de cenários (paisagens) e de ambientes (épocas) diferenciados que, segundo Velez de Castro e Almeida ${ }^{12}$ tanto podem ser de caráter intencional (reinterpretações) como tendo origem na ausência de consultoria científica (erros). Por isso Sarmento, Azevedo e Pimentainvocam Latour ao referir que "todos os ambientes e paisagens são co-produções de natureza-cultura" e por isso se referem a um determinado tempo ${ }^{13}$.

Neste contexto, invoca-se a visão de Meirelles, ao defender que pelo “(...) filme, podemos observar nos seus personagens a distribuição dos papéis sociais e os esquemas culturais que identificam os seus lugares na sociedade. As lutas, as reivindicações e desafios presentes no enredo, os diversos grupos envolvidos nessas ações. O modo como aparece representada a organização social, as hierarquias e as relações sociais. Como são percebidos e mostrados pelos cineastas: lugares [e] fatos (...) "'14. Ou seja, perante a perspetiva destes autores, está justificada a importância do cinema para explicar a cronotopia dos factos, pelo que faz sentido entender o filme como instrumento de trabalho em contexto científico.

${ }^{11}$ Tiago Reigada, Ensinar com a Sétima Arte: o espaço do cinema na ditática da história, Porto, Universidade do Porto, 2013, p. 37.

${ }^{12}$ Fátima Velez de Castro e António Campar de Almeida (2016). “Anatopias cinematográficas em contexto geográfico. Contributo para a (des)construção de paisagens imaginadas" in Fátima Velez de Castro e João Luís Fernandes, Territórios do Cinema. Representações e paisagens da pós-modernidade, Málaga, Eumed-Universidade de Málaga, 2016, p. 168.

${ }^{13}$ João Sarmento, Ana Francisca Azevedo, José Ramiro Pimenta, Ensaios de geografia cultural, Porto, Figueirinhas, 2006, p. 8.

${ }^{14}$ William Reis Meirelles, "O cinema na história. O uso do filme como recurso didático no ensino da história”, História e Ensino, 10 (2004), p. 78. 
O Cinema e a História: compreensão da dinâmica cronotópica das migrações contemporâneas a partir do filme

"The Immigrant", de Charlie Chaplin (1917)

\section{O filme como instrumento de trabalho em História}

Protat $^{15}$ afirma que desde o início do cinema, os criadores não têm parado de contar, recontar e recriar a História, tanto em dimensões mais ou menos fidedignas, como em versões que causam polémica junto dos estudiosos. Além deste autor, Smith ${ }^{16}$, Carlsten e McGarry ${ }^{17}$ destacam os anos 70 do séc. XX, como a década em que o cinema começa a ser usado como instrumento de investigação em história. São marcantes os trabalhos de Marc Ferro e Pierre Sorlin, na medida em que as obras fílmicas se passam a entender como um meio de obtenção de imagens, de experiências sensíveis, baseadas na interpretação e por vezes na própria vivência de fatos do passado.

Nesse sentido, o historiador é incitado a questionar e interpretar determinadas linhas historiográficas. É o que Morettin designa, em termos metodológicos, de "novo objeto"18. Mas não é só a partir dos anos 70 do séc. XX que se reconhece a importância do cinema para a investigação histórica, tanto mais que Schvarzman ${ }^{19}$ invoca Seignobos e Langlois, os quais já em 1898 se tinham referido à importância das obras literárias e teatrais para conhecer períodos da história onde a documentação não era abundante. No entanto, entre esta conceção e a nova perspetiva histórico-cinematográfica, há um hiato de mais de meio século. A investigação de Marc Ferro nos anos 60 do séc. XX levou-o a consultar imagens sobre a Primeira Guerra Mundial, de onde surgiu a ideia de que o cinema podia levantar novas pistas de interpretação dos fatos históricos.

A relação entre a História e o cinema é reciproca, pois se, por um lado, o historiador se interessa pelo filme como documento de análise, o cineasta inspira-se em fatos do passado para construir as suas imagens. Protat ${ }^{20}$ admite que esta dinâmica se gera com o próprio advento do cinema, nas primeiras obras produzidas. Veja-se o caso da curta-metragem "The Execution of Mary Stuart",

${ }^{15}$ Zoé Protat (2009), "Cinéma et histoire: reconstruir les temps, ressentir l'histoire”, cit., p. 40 .

${ }^{16}$ Paul Smith (1976), The historian and film, Londres, Cambridge University Press, 1976, p. 3.

${ }^{17}$ Jennie Carlsten and Fearghal McGarry, Film, History and Memory, Reino Unido, Palgrave-MacMillan, 2015, p. 4.

${ }^{18}$ Eduardo Victorio Morettin, "O cinema como fonte histórica na obra de Marc Ferro", cit., p. 12.

${ }^{19}$ Sheila Schvarzman, "Construindo a história na televisão: Marc Ferro e os Cinejornais em Histoire Parallèle”, Revista tempo, 20 (2014), p. 2.

${ }^{20}$ Zoé Protat (2009), "Cinéma et histoire: reconstruir les temps, ressentir l'histoire", cit., p. 43 . 
de Alfred Clark (1895), cuja ação se desenrola em torno de um tema histórico. Outros filmes povoam o imaginário do público, como o caso dos clássicos "Ben-Hur" (1925), de Fred Niblo; "Spartacus" (1960), de Stanley Kubrik; "Cleópatra" (1963), de Joseph L. Mankiewicz e Rouben Mamoulian; entre outros. Também Deshpand (2004: 4455) ${ }^{21}$ entende esta relação bidirecional, destacando duas posições: por um lado, considerando o cinema como uma fonte da História; por outro, considerando o cinema como uma forma diferente de abordar a própria História. Tendo em conta a reflexão de ambos os autores sobre visão do "cinema-fato" versus "cinema-interpretação", ainda se pode considerar uma terceira tipologia: a do "cinema-construção", ou seja, encarando-se como um construtor tempo-espaço.

Além de Ferro ${ }^{22}$, outros autores como Deshpand ${ }^{23}$ defendem que o historiador não pode ignorar o cinema e o filme na análise histórica, sob pena de eliminar um instrumento de trabalho válido e de descartar hipóteses de trabalho.

Também $\mathrm{Kaes}^{24}$ se apresenta como um autor de interesse, pois veio chamar a atenção para o perigo do cinema poder transformar a História numa sequência de imagens com pouco nexo. Este autor previu o fenómeno "zapping", gerado pela grande oferta de canais televisivos, o qual acaba por criar um efeito negativamente parcial de fatos histórico, vistos pelo telespetador de forma aleatória, sem uma lógica de continuidade ou de contextualização adequada. $\mathrm{Na}$ atualidade, todas as gerações, mas em especial os jovens, vivem emersos nas imagens (fixas e em movimento), sendo que enquanto objeto de pop culture, o cinema promove o aparente encurtamento das distâncias e o cosmopolitismo. Até fenómenos trágicos como a guerra se "higienizam", no sentido em que se aproximam e se tornam comuns nas visões da quotidianidade, confundindo-se por vezes com a realidade simulada dos videojogos, entendida como uma outra forma imagética de construir determinadas dinâmicas espácio-temporais.

Neste sentido, é importante que a academia esteja alerta para este fato, pelo que se torna urgente a produção de conteúdos científicos, onde seja realizada a análise fílmica, tanto do ponto de vista histórico e geográfico, como noutras perspetivas disciplinares. A ideia é oferecer ao telespetador-historiador, entre outros (por exemplo, telespetador-professor, telespetador-aluno, telespetador-

${ }^{21}$ Anirudh Deshpand, "Films as historical sources or alternative history", Economic and Political Weekly, 2-8 (2004), p. 4457.

${ }^{22}$ Marc Ferro, Cinema and history, cit., p. 23-24.

${ }^{23}$ Anirudh Deshpand, "Films as historical sources or alternative history", cit., p. 4455-4459 .

${ }^{24}$ Anton Kaes, "History and Film: public memory in the age of electronic dissemination", cit., p. 121. 
O Cinema e a História: compreensão da dinâmica cronotópica das migrações contemporâneas a partir do filme

"The Immigrant”, de Charlie Chaplin (1917)

-cidadão, etc), uma base analítico-científica, que permita entender o filme de forma holística, como instrumento complementar para compreensão da História, do espaço e da sociedade.

Reigada defende que "o cinema impõe-se (...) como uma fonte privilegiada para um olhar sobre a História dos sem história (...); assim, a memória assume-se como uma História alternativa que não aspira à objetividade científica, mas que questiona a subjetividade dos intervenientes e das suas ações. "25. Ou seja, este autor apela ao desenvolvimento do sentido crítico face a interpretações fatuais, onde o telespetador possa questionar e questionar-se sobre o grau de confiança sobre os fatos, a forma como ocorreram, como foram apresentados, entre outros aspetos. Só assim poderá compreender a História a partir do cinema, e o cinema enquanto veículo de transmissão da História. É por isso que, no âmbito da dimensão cronotópica das obras fílmicas, Rose ${ }^{26}$ destaca a importância do cinema por "criar-manipular" a dimensão visual, espacial e temporal, gerando novos mundos. Esta ideia é corroborada por Vieira e Velez de $\mathrm{Castro}^{27}$, que encaram esta arte como geradora da possibilidade contrapor e comparar a realidade particular conhecida, com a realidade coletiva desconhecida, ou seja, do(s) indivíduo(s) contatar(em) com o "outro".

Tendo como base esta ideia, será apresentado um estudo de caso no domínio da História das migrações, tendo como base analítica uma obra fílmica, a qual se assume como uma fonte de investigação de interesse, por retratar um cronotopos particular do início do séc. XX, que esteve na base da constituição do cenário migratório transatlântico contemporâneo.

\section{Caso de estudo: a compreensão migrações contemporâneas a partir do filme "The Immigrant", de Charlie Chaplin (1917)}

Charlie Chaplin é um dos realizadores-atores mais importantes da História do cinema. Para além de explorar novas vertentes cinematográficas do ponto de vista técnico e estético, deixou-nos um impressionante legado sobre os acontecimentos históricos da sua época, o séc. XX. Através de uma visão

${ }^{25}$ Tiago Reigada, Ensinar com a Sétima Arte: o espaço do cinema na ditática da história, cit., p. 46.

${ }^{26}$ Gilliam Rose, Visual methodologies. An introduction to researching with visual materials, Londres, Sage, 2012, p. 15.

${ }^{27}$ Rogéria Vieira e Fátima Velez de Castro, "O contributo do cinema para a educação geográfica. Um recurso didático em geografia das migrações”, GOT - Revista de Geografia e Ordenamento do Território, 9 (2016), p. 314. 
acutilante dos fenómenos, aliada a um espírito crítico notável, o telespetador tem ao seu dispor obras fílmicas de grande valor social.

Destaque-se o caso do filme "The Immigrant", de 191728, o qual é considerado, do ponto de vista histórico, a sua primeira grande obra. Larcher refere que "(...) Chaplin veste de novo o fato de vagabundo e desenvolve um enredo melodramático: (...) parte em auxílio de uma jovem num barco de emigrantes que ia a caminho de Nova Iorque. "29. Mas esta obra é mais do que isso, pois foca três momentos essenciais constituintes do projeto migratório: a viagem e as condições em que se opera; a chegada e o imediato da burocracia; a presença no território de destino e as condições iniciais de estabelecimento. No fundo, poderá ser entendido como um grito de protesto do realizador, no que diz respeito ao fechamento americano, ou melhor dizendo, às políticas migratórias restritivas de entrada nos EUA.

Vance $^{30}$ refere que Charlie Chaplin tinha um grande apreço por este seu filme, uma vez que se referia à sua própria experiência enquanto e/imigrante, e às dificuldades associadas à presença no país de migração. Veremos que o desenrolar da ação, assim como o desfecho do enredo, assentam numa perspetiva positiva sobre o grupo de imigrantes do filme em concreto, com a aura de "final feliz". Chaplin projeta-se nesta história/História, integrando-a como "personagem-ficcionada" e personagem-real", pois também ele e o irmão eram imigrantes britânicos nos Estados Unidos da América, e por isso vivenciaram o percurso e os obstáculos de muitos dos imigrantes retratados na película. Mas a projeção de si próprio ocorre também enquanto elemento externo ao drama das personagens estrangeiras, isto é, fazendo-se representar no agente que dá emprego a Chaplin e à sua amiga.

Assim, sendo dada a importância deste filme no contexto histórico-temático representado (as migrações transatlânticas do séc. XX), realizar-se-á uma análise de conteúdo das imagens fílmicas ${ }^{31}$. O objetivo é o de refletir sobre aspetos teórico-práticos em torno do tema da História e da Geografia das migrações, para facilitar a visualização e a discussão do filme em contexto académico.

${ }^{28}$ The immigrant (1917), Charlie Chaplin (real.), Dvd "Público".

${ }^{29}$ Jérôme Larcher, O livro Charlie Chaplin - Cahiers du Cinema, Lisboa, Público, 2008, p. 31 .

${ }^{30}$ Jeffrey Vance, Chaplin, genius of the cinema, Nova Iorque, Harry N. Abrams, 2003, 39.

${ }^{31}$ Gilliam Rose, Visual methodologies. An introduction to researching with visual materials, cit., p. 10. 
O Cinema e a História: compreensão da dinâmica cronotópica das migrações contemporâneas a partir do filme

"The Immigrant", de Charlie Chaplin (1917)

Relativamente à dimensão cronotópica, a obra enquadra-se no que Blanco ${ }^{32}$ designa de "ciclo das migrações transatlânticas", ocorridas no período moderno dos sistemas migratórios mundiais, onde se destaca o reforço do povoamento de origem europeia dos Estados Unidos da América. Observa-se também que as personagens representam, segundo Papademetriou ${ }^{33}$, migrantes legais, com (possível) permanência de longa duração, sendo portadores de documentação válida, ou seja, com autorização de entrada no país em causa. Segundo Martin e Midgley ${ }^{34}$ e Meissner et $a l^{35}$, Chaplin e todos os elementos do filme retratam a terceira fase da imigração para os Estados Unidos da América, que decorreu de 1880 a 1914. Os autores estimam que neste período tenham entrado nos EUA 20 milhões de migrantes oriundos da Europa do Sul e da Europa de Leste.

Fazendo uma análise dos momentos prototípicos do filme, identificam-se três núcleos de conteúdo, os quais são indicativos do percurso realizado pelos migrantes europeus com destino aos EUA.

O primeiro diz respeito à viagem. A cena inicial é a de um navio que, além de outros passageiros migrantes, transporta uma jovem mulher e a sua mãe viúva. Nesse grupo também viaja Chaplin, que aparece feliz e despreocupado a pescar um peixe. A sua atitude contrasta com os outros ocupantes do navio, os quais, visivelmente enjoados, se encontram deitados, numa tentativa de mitigar o incómodo e o mal-estar derivado do forte balanço do barco em mar alto. Os migrantes retratados no filme estão a responder a evidências enfatizadas por Massey et $a^{36}$, ou seja, a circunstâncias decorrentes de alterações sociais e políticas, tanto nas sociedades emissoras como nas recetoras, que os faz empreender uma viagem-migração longa e plena de obstáculos de várias índoles.

Pela visualização do cenário, sobretudo pelo pouco espaço destinado a um conjunto significativo de pessoas, assim como pela cena da refeição, leva-se a crer que se trata de migrantes com baixos recursos económicos, que fazem

${ }^{32}$ Cristina Blanco, Las migraciones contemporaneas, Madrid, Editora Alianza, 2000, p. 78 .

${ }^{33}$ Demetrious Papademetriou, A Europa e os seus imigrantes no séc. XXI, Lisboa, Fundação Luso-Americana para o Desenvolvimento, 2008, p. 21.

${ }^{34}$ Philip Martin and Elisabeth Midgley, "Immigration: shaping and reshaping America", Population Bulletin, 58-2 (2003), p. 12.

${ }^{35}$ Doris Meissner, Deborah Meyers, Demetrios Papademetriou and Michael Fix, Immigration and America's future: a new chapter, Estados Unidos, Migration Policy Institute, 2006, p. 2.

${ }^{36}$ Douglas Massey, Joaquín Arango, Graeme Hugo, Ali Kouaouchi, Adela Pellegrino y Taylor J. Edward, "Una evaluación de la teoría de la migración internacional: el caso de América del Norte" in Graciela Malgesini (ed.), Cruzando fonteras. Migraciones en el sistema mundial, Barcelona, Icaria, 1998, p. 247. 
a travessia num patamar de baixo custo. Focando-se a hora da alimentação, verifica-se que a comida é escassa, sendo servido um caldo que os passageiros comem avidamente. Chaplin aproveita para contar com sentido de humor como são as condições de viagem: com a contingência do balanço do barco, vê-se forçado a partilhar a comida com o passageiro que está na sua frente. O prato desliza entre os dois, num jogo metafórico que representa a escassez e as duras condições a que se submetem os migrantes durante a viagem.

Também é destacada outra cena, em que Chaplin joga com outros passageiros, com o objetivo de passar o tempo e de ganhar algum dinheiro, usando a habilidade e a sorte. Enquanto isso acontece, a viúva é defraudada por outro migrante, que lhe rouba todo o capital que possui para aplica-lo no jogo. Sem perceber o que se passa, Chaplin ganha a partida e arrecada todos os dividendos do viajante que roubou a viúva. Mais tarde, irá devolver esse valor à jovem rapariga, que lhe fica extremamente grata. Esta parte da história retrata o perigo da extorsão e do engano, associado tanto a agentes individuais como a grupos organizados de tráfico, que muitas vezes exploram os migrantes, aproveitando-se das suas fragilidades para lhes usurpar dinheiro. Neste caso, tratou-se de alguém do próprio grupo imigrante a realizar o crime, o que visou representar as dinâmicas transgressoras perpetradas no cerne da própria comunidade.

O segundo núcleo de conteúdo refere-se ao momento da chegada à terra da liberdade. É o instante mais curto deste filme (cerca 0:20), o qual tem, na totalidade, trinta minutos ${ }^{37}$. O navio faz menção de se dirigir para o porto, sendo que o realizador abre um plano sobre a estátua da liberdade. O grupo de migrantes, visivelmente entusiasmados, exibem rostos deslumbrados pela vista e pela chegada ao território de destino. Vislumbra-se nas suas expressões o sentimento de esperança. Esta reação está associada ao conceito de "imagem territorial", o qual diz respeito a um conjunto de expetativas sobre o território de destino migratório, e que é construído com base na recolha de informações originárias de diversas fontes, as quais se podem revelar distorcidas e distantes face à realidade. Manifesta-se por uma perceção positiva do território, o que parece estar de acordo com o esperado por este grupo de viajantes, tendo em conta as expressões e reação de satisfação manifestada aquando da chegada ao destino.

Observa-se que os imigrantes são "catalogados" e confinados por uma corda a um local que ainda não se pode considerar como sendo dos EUA. Trata-se do espaço-limbo que dá passagem ao país de destino, o que só poderá ocorrer

\footnotetext{
${ }^{37}$ Fonte da informação: www.imdb.com/title/tt0008133/ (acedido em 31/01/2017)
} 
depois dos trâmites burocráticos de verificação dos documentos. Trata-se da metáfora da fronteira, cujo jogo de aproximação-distância é perpetrado pelo poder das autoridades. É no Neste momento do filme destaca-se a concentração de pessoas num local exíguo do navio, sendo visível vestuário diverso, numa perspetiva comparativa, o qual representa as diversas origens geográficas e culturais dos imigrantes. Neste momento, Chaplin separa-se da jovem rapariga, com a qual travara amizade, e da sua mãe viúva.

O terceiro núcleo de conteúdo identificado é respeitante à vivência inicial no território de chegada. Mais tarde, com fome e sem dinheiro, Chaplin deambula pela rua. É no chão que encontra uma moeda e entra num restaurante para fazer uma refeição. Senta-se ao lado de um cliente que já come e o empregado parece fazer distinção entre ambos, o que levanta a dúvida: a atitude terá a ver com o fato de Chaplin representar um estrangeiro?

É aí que reencontra a sua amiga, que também tem fome e não tem dinheiro para fazer uma refeição. Chaplin pede um prato de feijões e pão para si e para a sua amiga. Nota-se que o vestuário da jovem já é diferente do usado na viagem, pois antes usava lenço na cabeça e roupas que se pareciam estar associadas a uma comunidade rural. Agora usa vestido e chapéu, o que se reflete no ar de sofisticação que transparece. Evidencia-se a presença de elementos da cultura urbana a serem integrados na identidade da jovem, numa lógica de reterritorialização $0^{38}$. Este conceito diz respeito a formas de apropriação realizadas pelos imigrantes nos territórios de chegada, com o propósito de reencontrar o seu equilíbrio identitário. Pode acontecer com base nas quotidianidades, seja através de ritos, práticas ou reproduções simbólicas. Neste caso foi através de um símbolo-externalidade: a roupa.

Chaplin percebe que não tem dinheiro para pagar e aflige-se (perdeu a moeda que tinha, pois, o bolso estava roto), no entanto tenta encontrar uma forma de o fazer. Outro cliente entra e mostra a moeda que irá usar para pagar a refeição (será imigrante?). O empregado guarda a moeda e, como (também) o bolso está roto, esta cai no chão. Chaplin usa-a para pagar a refeição, mas o empregado comprova que é falsa. Tanto ele como a jovem amiga sentem imenso medo da punição eminente, mas eis que surge o salvador: um cavalheiro (artista) paga-lhes a refeição, através da gorjeta. E ainda faz mais, contratando-os para trabalhar com ele no dia seguinte, pelo que lhes providencia alguns dólares de adiantamento.

\footnotetext{
${ }^{38}$ Rogério Haesbaert, O mito da desterritorialização, Rio de Janeiro, Bertrand Brasil, 2004, p. 38; João Luís Fernandes, "Paisagem cultural: de um espaço de reterritorialização ao recurso turístico", The Overarching Issues of European Space, (2013), p. 270.
} 
Este núcleo de imagens é muito importante por vários motivos. Além de dar pistas sobre o processo de reterritorialização dos migrantes, auxilia na compreensão das dificuldades sentidas pelos indivíduos no momento de chegada. Por um lado, fica a dúvida, se a reação do empregado poderá estar toldada por preconceitos contra estrangeiros; por outro, a dificuldade em ser produtivo numa fase inicial da migração, o que se reflete pela falta de rendimentos, que neste caso se materializou na dificuldade em aceder a bens básicos de carater alimentar. Por outro lado, a deambulação de Chaplin pela rua não parece ser uma cena ingénua, mas antes a representação da falta de orientação do projeto migratório em território "desconhecido". A personagem do empresário-artista, enquanto empregador, é de extrema importância: por um lado revela confiança no "outro", ao lhe dar trabalho e dinheiro; por outro reconhece o valor da mão-de-obra imigrante. Massey et a ${ }^{39}$ destaca, no sistema migratório americano, a influência atrativa do mercado-de-trabalho e dos ganhos decorrentes, que irão captar bastantes trabalhadores do continente europeu.

No final Charlie Chaplin casa com a jovem amiga. É a representação de um projeto migratório com final feliz, em que as personagens se parecem querer fixar de forma do território, estreitando laços pessoais através dos trâmites matrimoniais, que ocorrem oficialmente no país que os acolheu.

\section{Conclusão}

Este ano, o filme "The Immigrant", de Charlie Chaplin celebra o centenário do seu lançamento. Trata-se de uma obra ímpar para a História do cinema e para a História das migrações, ao retratar o fluxo de migrações transatlânticas do início do séc. XX, da Europa em direção aos EUA. As personagens do enredo são projeções das vivências do próprio realizador, que também ele foi imigrante nos EUA.

Tendo em conta a discussão realizada em torno da relação entre a História e o cinema, crê-se que este filme tem bastante interesse por dois motivos: por um lado, a montante do processo de investigação, por poder providenciar pistas sobre o tempo plasmado nas imagens, as quais estão patentes em diversas dimensões, isto é, tanto em termos cenográficos, como de guarda-roupa, passando pela forma como o enredo evolui e as personagens interpretam o seu papel, entre outros aspetos. Por outro, a jusante da dimensão científica, como

${ }^{39}$ Douglas Massey, Joaquín Arango, Graeme Hugo; Ali Kouaouchi, Adela Pellegrino and Taylor J. Edward, Worlds in motion. Understanding international migration at the end of the millennium, Oxford, Clarendon Press, 1998, p. 70. 
objeto analítico a ser explorado em contexto de ensino-aprendizagem, o qual poderá ocorrer em vários níveis de ensino.

Tendo em conta a dinâmica atual da Europa e dos EUA, enquadrados na perspetiva da História do Tempo Presente, urge a discussão em torno do fenómeno das migrações, no sentido de esclarecer tanto os investigadores, como os alunos, assim como a sociedade em geral, sobre a realidade fatual do cenário migratório internacional e da crise dos refugiados, com base em informações fidedignas e posições esclarecidas. Por isso se crê que, mais do que nunca, a História e o cinema têm um papel vital e uma responsabilidade acrescida na elucidação do que foi e do que é o fenómeno migratório na atualidade. 